\title{
Metabolomics demonstrates divergent responses of two Eucalyptus species to water stress
}

\author{
Charles R. Warren • Ismael Aranda • \\ F. Javier Cano
}

\begin{abstract}
Past studies of water stress in Eucalyptus spp. generally highlighted the role of fewer than five "important" metabolites, whereas recent metabolomic studies on other genera have shown tens of compounds are affected. There are currently no metabolite profiling data for responses of stress-tolerant species to water stress. We used GC-MS metabolite profiling to examine the response of leaf metabolites to a long ( 2 month) and severe $\left(\Psi_{\text {predawn }}<-2 \mathrm{MPa}\right)$ water stress in two species of the perennial tree genus Eucalyptus (the mesic Eucalyptus pauciflora and the semi-arid Eucalyptus dumosa). Polar metabolites in leaves were analysed by GC-MS and inorganic ions by capillary electrophoresis. Pressure-volume curves and metabolite measurements showed that water stress led to more negative osmotic potential and increased total osmotically active solutes in leaves of both species. Water stress affected around $30-40 \%$ of measured metabolites in E. dumosa and $10-15 \%$ in E. paucifora. There were many metabolites that were affected in $E$. dumosa but
\end{abstract}

\footnotetext{
C. R. Warren

School of Biological Sciences, Heydon-Laurence Building A08, University of Sydney, Sydney, NSW 2006, Australia

e-mail: charles.warren@sydney.edu.au

I. Aranda - F. J. Cano

Centro de Investigación Forestal, Instituto Nacional de Investigación y Tecnología Agraria y Alimentaria (INIA), Carretera de la Coruña km 7.5, 28040 Madrid, Spain

F. J. Cano

Unidad Docente de Anatomía, Fisiología y Genética Forestal, E.T.S.I. Montes, Universidad Politécnica de Madrid (UPM),

Ciudad Universitaria s/n, 28040 Madrid, Spain
}

not E. pauciflora, and some that had opposite responses in the two species. For example, in $E$. dumosa there were increases in five acyclic sugar alcohols and four lowabundance carbohydrates that were unaffected by water stress in E. paucifora. Re-watering increased osmotic potential and decreased total osmotically active solutes in E. pauciflora, whereas in E. dumosa re-watering led to further decreases in osmotic potential and increases in total osmotically active solutes. This experiment has added several extra dimensions to previous targeted analyses of water stress responses in Eucalyptus, and highlights that even species that are closely related (e.g. congeners) may respond differently to water stress and re-watering.

Keywords Drought - Metabolome - Osmotic adjustment . Water relations · GC-MS · Plant - Water stress

\section{Introduction}

Maintenance of turgor is a necessary prerequisite for cell enlargement and growth, and thus limited water supply can cause large reductions in plant growth (Hsiao 1973; Kramer and Boyer 1995). Nearly all plants can acclimate to water deficits, at least to some extent, by employing a range of responses to maintain cell turgor and growth under more negative soil water potentials than would otherwise be possible. These responses affect various aspects of physiology, biochemistry and molecular biology (Shao et al. 2009). In the case of the large Eucalyptus genus, for example, responses to water deficits include changes in biomass allocation (Rawat and Banerjee 1998), stomatal control (Macfarlane et al. 2004), cell wall reinforcement (Ladiges 1975), cell wall water storage (Tuomela 1997) and cellular osmolarity (Myers and Neales 1986; Lemcoff 
et al. 2002; Merchant et al. 2010). Additional responses to water deficits reported for other genera, and equally likely to co-occur in Eucalyptus, are increased amounts of antioxidants and antioxidant enzymes, and changes in the relative and absolute amounts of chlorophylls and carotenoids (e.g. Medrano et al. 2002; Shao et al. 2009).

One of the principal mechanisms by which plants cope with water deficits is osmotic adjustment, to maintain positive cell turgor via the active accumulation of solutes (Turner and Jones 1980; Morgan 1984; Turner 1986; Kramer and Boyer 1995). Reduction of osmotic potential permits maintenance of turgor and growth under water deficits by altering the turgor-raising potential of existing cellular water (for reviews see Turner and Jones 1980; Morgan 1984; Chaves et al. 2003). Typically organic solutes accumulate in the cytosol to counter concentrations of inorganic ions in vacuoles (thus contributing to osmotic balance between compartments, and overall turgor). Reductions in osmotic potential have been shown for many species and genera. Such reductions in osmotic potential can be attributed to active accumulation of solutes (osmotic adjustment), passive increases in solutes via reductions in cellular volume, or both. Reductions in osmotic potential have been attributed to a large number of individual compounds (e.g. proline, betaine) and classes of compounds (amino acids, cyclic and acyclic polyols, quaternary ammonium compounds) (reviewed in Chaves et al. 2003; Shao et al. 2009). For example, the amino acid proline may increase more than 100 -fold in response to water stress (Barnett and Naylor 1965; Hsiao 1973) and may permit tolerance of stress not only by osmotic adjustment, but also by protecting membranes and proteins, and/or by effects on metabolism (Hare et al. 1998). In the legume Lotus japonicus, proline and methylated inositols (e.g. pinitol, ononitol) tend to increase under salt stress and lead to osmotic adjustment (Sanchez et al. 2010). In contrast, in many Eucalyptus concentrations of proline are very small, do not necessarily increase under drought and never account for more than a few percent of total osmotic potential (Marsh and Adams 1995; Adams et al. 2005; Merchant et al. 2006b; Warren et al. 2007). Instead, leaves of some (but not all) Eucalyptus contain large constitutive amounts of the cyclohexanepentol proto-quercitol (Adams et al. 2005; Merchant et al. 2006b; Arndt et al. 2008), but increases in proto-quercitol due to drought tend to be small and thus its role (if any) in osmotic adjustment is unclear. Irrespective of whether a Eucalyptus species contains proto-quercitol, in Eucalyptus species the compounds most consistently associated with osmotic adjustment tend to be mono- and di-saccharides (Adams et al. 2005; Merchant et al. 2006b; Warren et al. 2007).

Historically a major limitation of studies examining responses of metabolites to water stress has been that most studies measured only one or two classes of compoundsleading to the somewhat biased and pre-ordained finding that the particular class of compounds is "important" while being blind to possible changes in other metabolites. Taking a metabolomic approach provides a less biased view of the metabolic phenotypes and can discover novel metabolic phenotypes that are missed by traditional targeted analyses (Fiehn 2002). There have been a number of metabolomic studies of water and/or salt stress in species that have limited tolerance to stress such as Arabidopsis, Pisum, Lolium and Lotus (Charlton et al. 2008; Foito et al. 2009; Lippold et al. 2009; Sanchez et al. 2010). Most of these studies imposed water stress rapidly and for a short period (generally less than 10 days), and thus may have been too rapid for prompting osmotic adjustment and changes in many metabolites, because these processes tend to be slow and may require several weeks (Turner 1986). Hence, it is unclear if the trends observed in stress-intolerant species exposed to rapid, short-term water stress are equally applicable to stress tolerant species (e.g. many evergreen trees and other perennials) exposed to a more ecologically realistic slow and prolonged water stress.

The genus Eucalyptus has been the subject of many studies examining responses of metabolites to drought, but all of these studies used targeted analyses of one or two classes of compounds (e.g. Adams et al. 2005; Merchant et al. 2006b; Warren et al. 2007). Here we build on this earlier literature by using a metabolomic approach to examine the response of leaf metabolites and water relations to a 2-month water stress treatment and subsequent re-watering. To establish the ubiquity of responses and provide insights into why Eucalyptus species vary in drought tolerance we contrast seedlings of the mesic subalpine species Eucalyptus pauciflora $(1200 \mathrm{~mm}$ annual rainfall in natural habitat) with the semi-arid species Eucalyptus dumosa $(400 \mathrm{~mm}$ annual rainfall in natural habitat). These species were chosen not only because they differ in drought tolerance but also because E. dumosa contains large amounts of proto-quercitol whereas $E$. pauciflora does not, and thus the two species serve as models to consider the broader implications of the dichotomy between species with and without proto-quercitol (Merchant et al. 2006b).

\section{Materials and methods}

\subsection{Chemicals}

The majority of approximately 130 chemical standards (purity >95\%) were purchased from Sigma-Aldrich (Sydney, Australia). Cyclohexanepentols and inositol stereoisomers were from TCI (Tokyo, Japan). The majority of standards 
were prepared in a 50:50 mixture of ultra-pure water $\left(18.2 \mathrm{M} \mathrm{cm}\right.$ at $\left.25^{\circ} \mathrm{C}\right)$ and methanol, while some were prepared in $0.05 \mathrm{M} \mathrm{NaOH}$ or $0.05 \mathrm{M} \mathrm{HCl}$. Pyridine (anhydrous), methanol, chloroform, methoxyamine hydrochloride, MSTFA and TMCS were from Sigma-Aldrich.

\subsection{Plant material and treatments}

Seeds of E. pauciflora (seedlot $19626,35^{\circ} 46^{\prime} \mathrm{S}, 148^{\circ} 58^{\prime} \mathrm{E}$, $1100 \mathrm{~m}$ above sea level) and $E$. dumosa (seedlot 18581 , $33^{\circ} 50^{\prime} \mathrm{S}, 146^{\circ} 37^{\prime} \mathrm{E}, 0 \mathrm{~m}$ above sea level) were obtained from the Australian Tree Seed Centre (Kingston, ACT, Australia). Seed of E. pauciflora was stratified at $4{ }^{\circ} \mathrm{C}$ for one month prior to germination. E. dumosa did not require stratification. Our aim was to compare similar-sized plants, and thus the slower growing $E$. dumosa was germinated on 12 March 2008 and E. pauciflora was germinated on 31 October 2008. Seeds of both species were germinated in wet vermiculite in a sunlit polythene-covered greenhouse that transmitted around $70 \%$ of sunlight. The mean temperature inside the greenhouse during the period of water stress and recovery (February-April 2009) was $22.1^{\circ} \mathrm{C}$ with an absolute maximum of $35.8^{\circ} \mathrm{C}$ and minimum of $11.7^{\circ} \mathrm{C}$. Average daily photosynthetically active radiation inside the greenhouse was $472 \mu \mathrm{mol} \mathrm{m} \mathrm{m}^{-2} \mathrm{~s}^{-1}\left(18.8 \mathrm{~mol} \mathrm{~m}^{-2} \mathrm{day}^{-1}\right)$ with an absolute maximum of $1701 \mu \mathrm{mol} \mathrm{m} \mathrm{m}^{-2} \mathrm{~s}^{-1}$. Once germinants had one pair of true leaves they were transferred to 2-1 pots filled with a commercial potting mix (Premium Potting mix, Yates, Padstow, NSW, Australia). The potting mix was derived from composted pine bark and contained micronutrients and slow-release fertiliser. Once seedlings were $20-\mathrm{cm}$ tall they were transferred to larger 8-1 pots filled with the same potting mix. Pots were watered to near field capacity with an automated drip irrigation system.

Water stress treatments began on the 20th of February when seedlings of both species were around $30-40 \mathrm{~cm}$ tall. Five replicate plants of both species were randomly chosen and assigned to a severe stress treatment, five were assigned to a moderate stress treatment and five were controls that were watered to near field capacity every day. Pots were randomly arranged in the greenhouse and re-arranged every 2 weeks for the duration of the treatments. Severe and moderate water stress were imposed by allowing pots to slowly dry down over a period of 2 weeks until stomatal conductance (measured with a LI-Cor LI-6400 under saturating light) was less than $0.05 \mathrm{~mol} \mathrm{~m}^{-2} \mathrm{~s}^{-1}$ for plants in the severe stress treatments and between 0.1 and $0.05 \mathrm{~mol} \mathrm{~m}^{-2} \mathrm{~s}^{-1}$ for plants in the moderate stress treatment. Stomatal conductance in control plants was always $>0.3 \mathrm{~mol} \mathrm{~m}^{-2} \mathrm{~s}^{-1}$. Once the target stomatal conductance was reached we continued to weigh pots every day and add enough water to replace what had been transpired in the previous day. Stomatal conductance was checked every 1-2 weeks and the watering regime adjusted as necessary. These water stress treatments were maintained for 8 weeks until the 9th of April when water-stressed plants were re-watered.

\subsection{Pre-dawn water potential and leaf water relations}

Predawn water potential $\left(\Psi_{\mathrm{pd}}\right)$ was measured in one leaf per plant with a pressure chamber (Soil Moisture Equipment Corp., Santa Barbara, California, USA) on the 9th of April before treatment plants were re-watered. To investigate leaf water relations we established pressure-volume curves (Tyree and Hammel 1972) by the free transpiration dehydration method (Hinckley et al. 1980). Measurements were made before treatments were imposed (17-18th of February), after drought had been imposed for 8 weeks (7-8th of April) and 2 days after re-watering (11-12th of April). Leaves were rehydrated (Dreyer et al. 1990) and pressure-volume curve parameters estimates as previously described (Tyree et al. 1978; Robichaux 1984; Kubiske and Abrams 1991).

\subsection{Leaf sampling and extraction for metabolites}

Leaf samples were collected on the 7 th of April, near the end of the drought treatment, and on the 13th of April, 4 days after plants had been re-watered. Samples were collected between noon and $1 \mathrm{pm}$ on sunlit days so as to collect samples when water stress is at its most severe (due to transpiration-induced decreases in $\Psi$ ) and to control for possible diurnal variation in metabolites. From each plant we punched four leaf discs $\left(0.56 \mathrm{~cm}^{2}\right.$ each) from the youngest fully expanded leaf into each of two 2-ml microfuge tube (Safe-Lock tube $2.0 \mathrm{ml}$, Eppendorf $\mathrm{AG}$, Hamburg, Germany). One of the 2-ml tubes was used for measuring metabolites and this tube was immediately frozen in liquid $\mathrm{N}$ and subsequently stored at $-80^{\circ} \mathrm{C}$. The other tube was used to measure the ratio of dry mass to leaf area and dry mass to fresh mass. Samples were subsequently entered into a laboratory information management system that provided codes for tracking samples and a randomisation schema for subsequent chemical analyses. The samples for measuring metabolites were freeze dried, weighed to the nearest $0.01 \mathrm{mg}$, and then ground to a fine powder with a bead mill $(30 \mathrm{~s}$ at $25 \mathrm{~Hz}$ with a $5 \mathrm{~mm}$ stainless steel bead) (TissueLyser, Qiagen, Doncaster, VIC, Australia). Metabolites were extracted with hot methanol:chloroform:water as previously described (Warren 2009). 
2.5 Untargeted analysis of aqueous metabolites as TMS derivatives

All samples were analysed by GC-MS as TMS derivatives with two electron impact (EI) ionisation methods: splitless injection with a slow temperature ramp and a separate split injection with a faster temperature ramp. Two separate injections were necessary because metabolite concentrations spanned more than five orders of magnitude, and thus the splitless method permitted ID of as many metabolites as possible but could not be used for quantification of abundant metabolites because they were well above the linear range. In addition, a subset of samples were analysed by methane chemical ionisation to assist in identification. Methoximated TMS derivatives were prepared essentially as described previously ( $\mathrm{Lisec}$ et al. 2006). $25 \mu \mathrm{l}$ of aqueous phase of methanol:chloroform:water extract plus $5 \mu \mathrm{l}$ of $0.2 \mathrm{mg} \mathrm{ml}^{-1}$ ribitol was dried under a stream of dry nitrogen gas, and then $40 \mu \mathrm{l}$ of methoxyamination reagent (20 $\mathrm{mg} \mathrm{ml}^{-1}$ methoxyamine hydrochloride in pyridine) was added and tubes were incubated for $90 \mathrm{~min}$ at $37^{\circ} \mathrm{C}$ in a shaking incubator ( $400 \mathrm{rpm}$ ). $70 \mu \mathrm{l}$ of $\mathrm{N}$-Methyl- $\mathrm{N}$-trifluoroacetamide (MSTFA) with $1 \%$ trimethylchlorosilane (TMCS) was added and tubes were incubated for $30 \mathrm{~min}$ at $37^{\circ} \mathrm{C}$ in a shaking incubator (400 rpm). Derivatised samples were cooled to room temperature and then transferred to a 2-ml glass GC vial with a $200-\mu l$ glass insert. Samples were derivatised and analysed in batches of 12 within $14 \mathrm{~h}$ of derivatisation. Each batch of samples included a quality control mixture of amino acids, a blank, and a retention index mix (even $n$-alkanes from $\mathrm{C} 10$ to $\mathrm{C} 40$ ). A $1 \mu \mathrm{l}$ sample was injected into an injection port liner (single gooseneck Siltek-treated, Restek, Bellefonte, PA, USA) at $250^{\circ} \mathrm{C}$ and was separation by capillary gas chromatography on an arylene-modified 5\% diphenyl-95\% dimethyl polysiloxane stationary phase $(30 \mathrm{~m}$ long $\times 0.25 \mathrm{~mm}$ ID $\times 0.25 \mu \mathrm{m}$ film thickness with a $10-\mathrm{m}$ "guard column"; Rxi-5SilMS, Restek, Bellfonte, USA). The column was held at $70^{\circ} \mathrm{C}$ for $2 \mathrm{~min}$, raised to $330^{\circ} \mathrm{C}$ at $8^{\circ} \mathrm{C} \mathrm{min}^{-1}$, and then held at $330^{\circ} \mathrm{C}$ for $10 \mathrm{~min}$. Helium $(99.999 \%$, BOC, North Ryde, NSW, Australia) was used as the carrier gas at a constant flow of $1 \mathrm{ml} \mathrm{min}{ }^{-1}$. The transfer line was held at $280^{\circ} \mathrm{C}$ and the ion source at $250^{\circ} \mathrm{C}$. The column eluent was ionised by electron impact $(70 \mathrm{eV})$ and mass spectra were collected from 70 to $600 \mathrm{amu}$ at 6.67 scans per second (GCMS-QP2010Plus, Shimadzu, Kyoto, Japan). To quantify abundant metabolites, all samples were analysed using a faster split injection method. $1 \mu \mathrm{l}$ samples were injected with a 20:1 to 30:1 split into an injection port liner (FocusLiner ${ }^{\mathrm{TM}}$, SGE, Ringwood, VIC, Australia) at $275^{\circ} \mathrm{C}$. We used a higher injection port temperature for split analysis because it improved relative peak responses for high boiling compounds (e.g. di- and tri-saccharides, catechins). The same Rxi-5SilMS column was used, but carrier gas flow was $1.5 \mathrm{ml} \mathrm{min}^{-1}$ and the column was held at $130^{\circ} \mathrm{C}$ for $1 \mathrm{~min}$, ramped to $330^{\circ} \mathrm{C}$ at $15^{\circ} \mathrm{C} \mathrm{min}-1$ and held at $330^{\circ} \mathrm{C}$ for $6 \mathrm{~min}$. MS acquisition parameters were as described above for splitless analysis. Two methoximated TMS samples from each species and treatment were analysed by GC-MS with methane chemical ionisation (CI) to confirm identification of metabolites. Methane CI used the same chromatographic conditions as were used for splitless analysis (described above), but an ion source temperature of $150^{\circ} \mathrm{C}$ and pressure of $6.0-6.5 \times 10^{-4} \mathrm{~Pa}$ (vs. $1.0 \times 10^{-4} \mathrm{~Pa}$ without reagent gas). Mass spectra were collected from 65 to $1000 \mathrm{amu}$ at 3 scans per second.

\subsection{Targeted analysis of amino acids as $t$-BDMS derivatives}

Amino acids were quantified as tert-butyldimethyl-silyl ( $t$-BDMS) derivatives (Mawhinney et al. 1986). $25 \mu \mathrm{lali}$ quot of the aqueous fraction of a sample plus $5 \mu$ of internal standard $\left(0.1 \mathrm{mg} \mathrm{ml}^{-1}\right.$ norleucine) was dried, re-dissolved in $100 \mu \mathrm{l}$ of $N, N$-dimethylformamide and derivatised with50 $\mu \mathrm{l}$ of $N$-methyl- $N$-[tert-butyldimethyl-silyl]trifluoroacetimide by heating at $80^{\circ} \mathrm{C}$ for $45 \mathrm{~min} .1 \mu \mathrm{l}$ samples were injected with a 10:1 split into an injection port liner (FocusLiner ${ }^{\mathrm{TM}}$, SGE, Ringwood, VIC, Australia) at $250^{\circ} \mathrm{C}$ and separated by capillary gas chromatography on the same Rxi-5SilMS column. The column was held at $130^{\circ} \mathrm{C}$ for $2 \mathrm{~min}$, raised to $330^{\circ} \mathrm{C}$ at $10^{\circ} \mathrm{C} \mathrm{min}{ }^{-1}$, and then held at $330^{\circ} \mathrm{C}$ for $10 \mathrm{~min}$. Helium was used as the carrier gas at a constant flow of $1 \mathrm{ml} \mathrm{min}^{-1}$. The transfer line was held at $280^{\circ} \mathrm{C}$ and the ion source at $250^{\circ} \mathrm{C}$. The column eluent was ionised by electron impact $(70 \mathrm{eV})$ and mass spectra were collected from 100 to $600 \mathrm{amu}$ at 4 scans per second. Amino acids were identified based on retention indices and mass spectra of authentic standards run under the same conditions: RI match within 5 units, reverse spectral match better than $80 \%$, and the ratio of quantification ion to two qualifier ions. Quantification was based on a 5-point standard curve $\left(0.004-40 \mu \mathrm{g} \mathrm{ml}^{-1}, \mathrm{R}^{2}>0.98\right)$ with the dominant M-57 ions (ions with a mass 57 less than the intact molecular ion-corresponding to loss of a $t$-butyl group), with the exception of arginine which was quantified based on the dominant M-188 ion (corresponding to loss of a $t$-butyl group plus a guanidino $\mathrm{N}$ ).

\subsection{GC-MS maintenance and QC}

Injection port liners and septa were replaced after every 30-36 injections. Trimming of the column and cleaning of the injection port were performed when the ratio of Asn to Ser in the quality control mixture of amino acids decreased by more than $30 \%$ from values recorded for a clean 
injection port and new column (typically after 150-250 samples). The EI ion source was generally cleaned at the same time as "front end" maintenance, or when m/z 502 of PFTBA tuning compound decreased below $2.5 \%$ (vs. $4-5 \%$ for a clean ion source). The GC column was replaced when its performance could not be restored by "front end" maintenance (typically after 800-1200 samples).

\subsection{Identification of TMS derivatives}

To identify methoxymated TMS metabolites, EI chromatograms were exported from the proprietary Shimadzu format to netCDF and deconvoluted (AnalyzerPro, Spectralworks Ltd., Runcorn, UK). Metabolites were identified by comparing retention indices and mass spectra with a laboratory mass spectral/retention index library plus the Golm Metabolome Database (GMD, Schauer et al. 2005), Agilent Fiehn and NIST libraries. The laboratory library for common metabolites was based on 130 chemical standards ( $\geq 95 \%$ purity) that covered the major classes of metabolites (organic acids, amino acids, mono-saccharides, di-saccharides, inositols, sugar phosphates, phenols) and included key compounds not present in other mass spectral databases (e.g. proto- and epi-quercitol, isomers of myoinositol). Analysis of around 100 chemical standards common to all three libraries revealed a strong relationship between the experimentally determined retention index and those quoted in GMD $\left(\mathrm{R}^{2}=0.9997\right)$ and Fiehn $\left(\mathrm{R}^{2}=0.9996\right)$. These relationships were used to adjust retention indices of GMD and Fiehn libraries. Criteria used in identification were retention index \pm 5 units and mass spectral match $>75 \%$. Unidentified metabolites appearing in $>50 \%$ of samples from a species were given a unique identifier (EIMS_retention index) and entered into the laboratory mass spectral/retention index library. Analysis of a sub-set of samples with methane CI provided a second check on identification. 72 chemical standards were analysed by methane $\mathrm{CI}$ to produce a rudimentary library and identify fragmentation patterns of common metabolite classes. High-mass fragments (e.g. $[\mathrm{MH}]^{+}$) in methane CI permitted identification of characteristic fragment ions for classes of metabolites and these combined with neutral losses were used to verify compounds identified from EI and to probe CI chromatograms for unidentified peaks (e.g. of compounds like cyclohexanetetrols that have readily predictable mass spectra but do not exist in EI libraries or as purified standards).

To quantify all identified and unidentified metabolites detected by deconvolution (see above) we created a peak table in GCMS Postrun analysis software (V2.5, Shimadzu). Chromatograms were integrated without any smoothing or minimum area restrictions, but with a minimum width of $0.1 \mathrm{~s}$ and slope of $100 / \mathrm{min}$. Metabolites in the peak table were identified based on RI match within 5 units, reverse mass spectral match better than $80 \%$, and the ratio of quantification ion to two qualifier ions. Absolute and relative quantification was based on carefully selected quantification ions. All chromatograms were checked by hand to remove integration errors and mass spectral peaks due to contaminants (e.g. siloxanes). Relative quantification was based on peak areas relative to the internal standard (ribitol). Absolute quantification was based on separate 3-point standard curves for splitless $\left(0.004-40 \mu \mathrm{g} \mathrm{ml}^{-1}, \quad \mathrm{R}^{2}>0.98\right)$ and split injection (4 $-1 \mathrm{mg} \mathrm{ml}^{-1}, \mathrm{R}^{2}>0.98$ ). Both standard curves were well within the linear range of the MS detector. Limits of detection ( $3 \times$ signal to noise) varied among metabolites but were generally $0.001 \mu \mathrm{g} \mathrm{ml}^{-1}$ of extract, or $0.04 \mu \mathrm{g} \mathrm{kg}^{-1}$ of dry plant material.

\subsection{Targeted analysis of inorganic anions and cations}

Inorganic anions and cations were determined by capillary electrophoresis with indirect UV detection, essentially as described previously (Warren and Adams 2004). Separations and quantification was performed with a commercial CE system (P/ACE MDQ, Beckman-Coulter Inc, Fullerton, CA, USA) with a $50 \mu \mathrm{m}$ i.d. $\times 50 \mathrm{~cm}$ capillary of bare fused silica. Samples were diluted fivefold prior to analysis. The major metal cations and ammonium were analysed with a background electrolyte of $10 \mathrm{mM}$ imidazole, $2 \mathrm{mM}$ 18-crown- 6 at $\mathrm{pH} 4.2$. Cations were injected by pressure ( $5 \mathrm{psi} \mathrm{s}$ ), separated at $25 \mathrm{kV}$ (normal polarity), $20^{\circ} \mathrm{C}$, and detected by indirect UV at $200 \mathrm{~nm}$. Anions were analysed with a background electrolyte of $20 \mathrm{mM} \mathrm{2,6}$ pyridinedicarboxylic acid, $0.5 \mathrm{mM}$ cetyltrimethylammonium bromide at $\mathrm{pH}$ 5.6. Anions were injected by pressure (5 psi s), separated at $25 \mathrm{kV}$ (reverse polarity), $20^{\circ} \mathrm{C}$, and detected by indirect UV at $214 \mathrm{~nm}$. Inorganic ions were identified based on migration time of authentic standards. Quantification was with external standards.

\subsection{Statistics}

Univariate statistics ( $t$ tests and ANOVA) were used to examine the effect of water stress and re-watering on leaf water relations and metabolite concentrations. Analyses of leaf metabolites were generally based on amounts per unit dry mass, but key data are also presented on the basis of amounts per unit of leaf water to aid interpretation in the context of osmotically active substances. To perform multivariate statistics, we constructed separate sample matrices for the two species. The sample matrix contained combined data of TMS derivatives, $t$-BDMS derivatives and capillary electrophoresis. In cases where a metabolite had been measured by more than one method, we used only 
the most reliable measurements (e.g. $t$-BDMS derivatives for amino acids, capillary electrophoresis for phosphate). TMS commonly produces multiple derivatives of the one metabolite, but for metabolites with multiple derivatives we created one "synthetic peak". This pre-processing step involved either an averaging of the multiple peaks per metabolite (in cases where peak areas were similar), or deletion of those peaks that were deemed less reliable (e.g. low abundance peaks). We omitted those metabolites that were not present in at least $50 \%$ of samples in either species. Data were Pareto scaled and log transformed and then multivariate statistics were performed with SLMCA P+ 12.01 (Umetrics AB, Sweden). Before performing analyses we checked for the presence of outliers and coding errors using principal components analysis. OPLS-DA was used to separate predictive variation related to the treatments, from non-predictive (orthogonal) variation.

\section{Results}

\subsection{Pre-dawn water potential and leaf water relations}

The predawn leaf water potential $\left(\Psi_{\mathrm{pd}}\right)$ was -1.4 to $-2.4 \mathrm{MPa}$ in the moderate stress treatment and -2.8 to $-3.8 \mathrm{MPa}$ in the severe stress treatment (Table 1). $\Psi_{\mathrm{pd}}$ was generally more negative in $E$. dumosa than $E$. pauciflora (Table 1). Leaf water relations parameters differed between species and were affected by water stress (Table 1). In E. dumosa osmotic potentials ( $\Pi^{100}$ and $\Pi^{0}$ ) were more negative and osmotically active solutes $\left(\mathrm{N}_{\mathrm{s}}\right)$ more concentrated than in E. paucifora. Bulk elastic modulus ( $\varepsilon_{\max }$ ) of $E$. dumosa was $10-20 \%$ larger than in $E$. pauciflora. In both species $\Pi^{100}$ was more negative and osmotically active solutes were greater in plants exposed to water stress (i.e. osmotic adjustment occurred) (see OA and $\mathrm{N}_{\mathrm{s}}$ in Table 1, or Fig. 1). The size of osmotic adjustment was larger in $E$. dumosa than E. pauciflora, with a maximum osmotic adjustment of $0.5 \mathrm{MPa}$ for $E$. dumosa and 0.2 for E. pauciflora (Table 1). The bulk modulus of elasticity was larger in water stressed plants than controls, while the apoplasmic water content was lower in water stressed plants than in controls. $\mathrm{RWC}^{0}$ was around $85 \%$ in most plants (including plants after re-watering). Re-watering of moderately stressed E. dumosa and E. pauciflora increased $\Psi_{\mathrm{pd}}$ to control values. In severely stressed E. pauciflora $\Psi_{\mathrm{pd}}$ increased to control values, whereas in severely stressed $E$. dumosa re-watering increased $\Psi_{\mathrm{pd}}$ from -3.8 to $-0.1 \mathrm{MPa}$ (vs. $-0.01 \mathrm{MPa}$ in controls). In E. dumosa re-watering led to a more negative osmotic potential, whereas in E. pauciflora osmotic potential increased (and $\mathrm{N}_{\mathrm{s}}$ decreased) (Fig. 1).

\subsection{Leaf metabolites}

In E. pauciflora 110 metabolites were above detection and quantification limits in at least $50 \%$ of samples, while in $E$. dumosa 115 metabolites were above detection and quantification limits in at least $50 \%$ of samples (see Supplementary Material). 8 metabolites detected in E. pauciflora were absent or below detection limits in E. dumosa, while 19 metabolites detected in $E$. dumosa were absent or below detection limits in $E$. pauciflora. Of the 124 metabolites reported, 78 have been positively identified (according to MSI criteria Sumner et al. 2007), 16 have been putatively identified (RI \& mass spectra match vs. GMD or Fiehn libraries), 12 correspond to unknowns listed in GMD, and 18 do not match any library entries. For some of the 18 unknowns there were mass spectral matches to EI and CI libraries, suggesting occurrence of isomers.

The total concentration of measured solutes in control E. dumosa was $1375 \mathrm{mmol} \mathrm{kg} \mathrm{leaf}$ water $^{-1}(815 \mathrm{mmol} \mathrm{kg}$ dry $\mathrm{mass}^{-1}$ ), while in control E. pauciflora it was $1473 \mathrm{mmol} \mathrm{kg}$ leaf water $^{-1}\left(1004 \mathrm{mmol} \mathrm{kg} \mathrm{dry} \mathrm{mass}{ }^{-1}\right)$ (Fig. 2). In control plants inorganic anions and cations were $55-60 \%$ of total measured solutes, and there was no difference between species in the relative amounts of the different inorganic anions and cations. In contrast, there were large differences between species in the relative and absolute amounts of some of the major organic metabolites. $E$. dumosa contained large amounts of the cyclohexanepentol proto-quercitol $\left(115 \mathrm{mmol} \mathrm{kg}\right.$ leaf water $^{-1}$, $68 \mathrm{mmol} \mathrm{kg}$ dry mass ${ }^{-1}, 1.1 \%$ of dry mass), and all E. dumosa replicates contained small amounts of viboquercitol and two unidentified cyclohexanepentol stereoisomers (RI $=1764$ and 1871). Some E. dumosa samples also contained trace amounts of epi-quercitol and another unidentified cyclohexanepentol $(\mathrm{RI}=1768)$, but these were excluded from further analyses because they occurred in fewer than $50 \%$ of samples. In E. pauciflora cyclohexanepentols were either absent or below detection limits. The most abundant organic solute in E. pauciflora was shikimic acid $\left(251 \mathrm{mmol} \mathrm{kg}\right.$ leaf water $^{-1}, 171 \mathrm{mmol} \mathrm{kg}$ dry mass ${ }^{-1}, 2.9 \%$ of dry mass), which equated to 300 times more than in E. dumosa $\left(0.7 \mathrm{mmol} \mathrm{kg}\right.$ leaf water ${ }^{-1}$, $0.4 \mathrm{mmol} \mathrm{kg} \mathrm{dry} \mathrm{mass}^{-1}$ ). Both species contained similar amounts of the cyclohexanehexol myo-inositol, but E. pauciflora also contained the cyclohexanehexol scylloinositol. E. paucifora contained approximately ten times more galactinol than $E$. dumosa. In both species amino acids were less than $2 \%$ of all solutes.

\subsection{Effects of water stress on leaf metabolites}

In both species the moderate stress treatment was intermediate between control and severely stressed plants. The 
Table 1 Leaf water relations parameters of $E$. dumosa and E. pauciflora grown with adequate water (control) or subjected to moderate or severe water stress for 2 months

\begin{tabular}{|c|c|c|c|c|c|}
\hline & \multicolumn{3}{|l|}{ Water stress } & \multicolumn{2}{|l|}{ Re-watered } \\
\hline & Control & Moderate stress & Severe stress & Moderate stress & Severe stress \\
\hline \multicolumn{6}{|l|}{$\varepsilon_{\max }(\mathrm{MPa})$} \\
\hline E. dumosa & $13.6(1.4) \mathrm{ab}$ & $17.2(1.5) \mathrm{d}$ & $17.1(1.3) \mathrm{d}$ & $14.9(2.0)$ & $12.6(2.0)^{* * *}$ \\
\hline E. pauciflora & $12.2(2.0) \mathrm{a}$ & $15.8(1.2) \mathrm{cd}$ & $14.2(0.8) b c$ & $11.9(1.3)^{* * *}$ & $12.3(1.2)^{*}$ \\
\hline \multicolumn{6}{|l|}{$\mathrm{N}_{\mathrm{s}}\left(\mathrm{mol} \mathrm{g}^{-1}\right)$} \\
\hline E. dumasa & $1.2(0.1) \mathrm{a}$ & $1.2(0.1) \mathrm{ab}$ & $1.5(0.2) \mathrm{c}$ & $1.1(0.2)$ & $1.1(0.1)^{* * *}$ \\
\hline E. pauciflara & $1.0(0.2) \mathrm{a}$ & $1.4(0.1) \mathrm{bc}$ & $1.4(0.1) \mathrm{c}$ & $1.0(0.2)^{* *}$ & $1.1(0.1)^{* * *}$ \\
\hline \multicolumn{6}{|l|}{$\mathrm{OA}(\mathrm{MPa})$} \\
\hline E. dumosa & - & 0.3 & 0.5 & 0.5 & 0.6 \\
\hline E. pauciflora & - & 0.1 & 0.2 & 0.0 & 0.1 \\
\hline \multicolumn{6}{|l|}{$\mathrm{R}_{\mathrm{a}}(\%)$} \\
\hline E. dumosa & $11.1(4.2) \mathrm{a}$ & $4.8(3.4) \mathrm{a}$ & $4.5(2.2) \mathrm{a}$ & $19.6(9.9)^{*}$ & $29.1(3.9)^{* * * *}$ \\
\hline E. pauciflora & $21.9(11.3) b$ & $9.5(4.4) \mathrm{a}$ & $4.2(1.9) \mathrm{a}$ & $24.3(10.3)^{*}$ & $17.4(3.0)^{* * * *}$ \\
\hline \multicolumn{6}{|l|}{$\Psi_{\mathrm{pd}}(\mathrm{MPa})$} \\
\hline E. dumosa & $-0.01(0.00) \mathrm{a}$ & $-2.4(0.4) \mathrm{c}$ & $-3.8(0.6) \mathrm{d}$ & $-0.01(0.01)^{* * * *}$ & $-0.01(0.03) * * * *$ \\
\hline E. pauciflora & $-0.01(0.00) \mathrm{a}$ & $-1.4(0.4) b$ & $-2.9(0.5) \mathrm{c}$ & $-0.01(0.00)^{* * * *}$ & $-0.01(0.01)^{* * * * *}$ \\
\hline
\end{tabular}

Three days after re-watering parameters were re-measured in plants that were previously moderately or severely stressed. Data are: maximum bulk modulus of elasticity at full turgor $\left(\varepsilon_{\max }\right)$, osmotically active solutes $\left(\mathrm{N}_{\mathrm{s}}\right)$, osmotic adjustment $(\mathrm{OA})$, relative water content of the apoplasmic fraction $\left(R_{\mathrm{a}}\right)$ and predawn water potential $\left(\Psi_{\mathrm{pd}}\right)$

The significance of differences among control, moderate and severe stress was determined by Duncan's test and different groups are indicated by letters

The significance of re-watering was tested by "repeated measures ANOVA" and is shown with asterisks: *** $P<0.001$; *** $P<0.01$; $* P<0.05$. Data are means (sd) of five replicate plants

moderate stress treatment has been omitted to simplify statistical analyses and interpretation or metabolites. The total concentration of measured solutes was greater in water stressed E. dumosa $\left(1610 \mathrm{mmol} \mathrm{kg}\right.$ leaf water $\left.{ }^{-1}\right)$ than controls (1375 mmol kg leaf water $\left.{ }^{-1}\right)$, and in water stressed E. pauciflora $\left(1663 \mathrm{mmol} \mathrm{kg}\right.$ leaf water $\left.^{-1}\right)$ than controls $\left(1473 \mathrm{mmol} \mathrm{kg}\right.$ leaf water $\left.^{-1}\right)$. These trends in total measured solutes paralleled estimates of solutes from pressure-volume curves (see $\mathrm{N}_{\mathrm{s}}$ in Table 1). OPLS-DA was used to separate multivariate relationships into predictive variation (related to treatments) and orthogonal variation (unrelated to treatments). In both species OPLSDA produced reasonable models $\left(R^{2} Y>0.98\right.$ and $\mathrm{Q}^{2}>0.7$ in both species), that were significant (CVANOVA, $P<0.05$ ) and analysis of the scores plots (first predictive component vs. first orthogonal component) showed complete separation of control plants from water stressed plants (data not shown) (Fig. 3). Metabolites identified as "significant" based on loadings in the OPLSDA models (see Supplementary Material) were generally also found to be significant in univariate analysis of metabolite concentrations (see Fig. 4 and Supplementary Material).

In E. dumosa water stress affected multiple aspects of carbohydrate metabolism, but had minor effects elsewhere.
There were increases in galactose, fructose, glucose, and monosaccharides, sugar acids and acyclic sugar alcohols derived from galactose, fructose, glucose (Fig. 4). At the same time there were decreases in compounds that are part of the raffinose/stachyose biosynthetic pathway: galactinol (threefold decrease), myo-inositol (1.7-fold decrease) and raffinose ( 2.5 -fold decrease). There were notable increases in cyclohexanepentols: vibo-quercitol (23-fold increase), cyclohexanepentol_1 (ninefold increase), cyclohexanepentol_2 (2.4-fold increase), proto-quercitol (1.5-fold increase). There were also increases in hydroxyproline, malic acid and dehydroascorbate (twofold increase). In terms of contribution to more negative osmotic potential under water stress (Fig. 1), the major contributors were fructose, glucose, malic acid and proto-quercitol owing to their large constitutive concentrations (Fig. 2).

Water stress affected fewer metabolites in E. pauciflora. There were increases in glucose (3.5-fold increase), fructose (3.5-fold increase), sucrose (1.4-fold increase), galactinol (1.6-fold increase). At the same time there were decreases in two acyclic sugar alcohols (arabitol and glucitol; 4- and 1.5-fold decreases), catechin (3.5-fold decrease), shikimic acid (1.3-fold increase), glyceric acid (1.1-fold increase) and valine (3.8-fold increase). The major contributors to more negative osmotic potential 


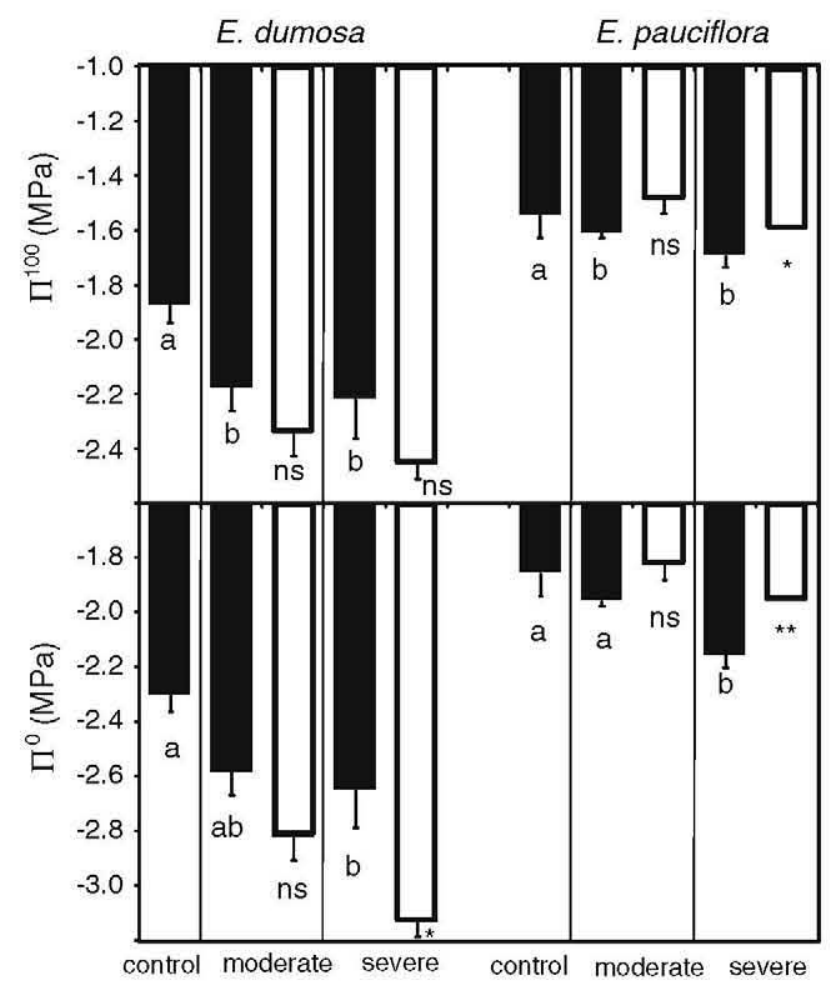

Fig. 1 Osmotic potential at full turgor $\left(\Pi^{100}, \mathrm{MPa}\right)$ and the point of loss turgor ( $\Pi^{0}, \mathrm{MPa}$ ) in E. dumosa (left side) and E pauciflora (right side) grown with adequate water (control) or exposed to moderate or severe water stress for 2 months. Osmotic potential was estimated from pressure-volume curves at the end of water stress period (filled columns) and 3 days after re-watering (hollow columns). Letters indicate significant differences among water stress treatments (Duncan's test), while stars show statistical differences between the same plants measured under water stress and after re-watering (repeated measures ANOVA: ${ }^{*} P<<0.01 ; * P<0.05$; ns $P>0.05$ ). Data are means and standard errors of five replicate plants under water stress were fructose, glucose and sucrose owing to their large constitutive concentrations (Fig. 2).

\subsection{Effects of re-watering water-stressed plants}

Re-watering increased the total concentration of measured solutes in $E$. dumosa (re-watered $=1719 \mathrm{mmol} \mathrm{kg}$ leaf water $^{-1}$; water stressed $=1610 \mathrm{mmol} \mathrm{kg} \mathrm{leaf} \mathrm{water}^{-1}$ ) but decreased the concentration in E. pauciflora (re-watered $=1323 \mathrm{mmol} \mathrm{kg}$ leaf water $^{-1}$; water stressed $=$

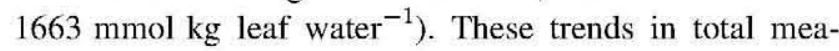
sured solutes paralleled estimates of osmotically active solutes derived from pressure-volume curves $\left(\mathrm{N}_{\mathrm{s}}\right.$ in Table 1). OPLS-DA models of stressed versus re-watered plants were comparatively poor $\left(R^{2} Y>0.94\right.$ and $\mathrm{Q}^{2}=0.34-0.38$ ), indicating that re-watering had a modest effect on the multivariate data structure.

In $E$. dumosa 39 metabolites were decreased by water stress, with 28 out of 39 representing a reversal of waterstress induced increases (Fig. 5). Nine of the 39 metabolites that decreased upon re-watering were apparently unaffected by water stress, though closer examination of the data shows that for most of these metabolites (e.g. Glc-6-P, Fig. 4) there were non-significant increases under water stress. In myo-inositol and raffinose re-watering led to additional decreases in concentration. Re-watering did not change amounts of any cyclohexanepentols, fructose, or glucose despite their strong increases in response to water stress (Fig. 5).

In E. pauciflora re-watered plants differed from stressed plants by way of increases in 13 metabolites and decreases in eight. The metabolites that increased upon re-watering
Fig. 2 Concentration (in mmol kg leaf water ${ }^{-1}$ ) of major solutes in leaves of $E$. dumosa and $E$. pauciflora grown with adequate water (control). Data are mean of five replicate plants per species. Proto-quercitol in E. dumosa is $1.1 \%$ of dry mass and shikimic acid in $E$. pauciflora is $2.9 \%$ of dry mass

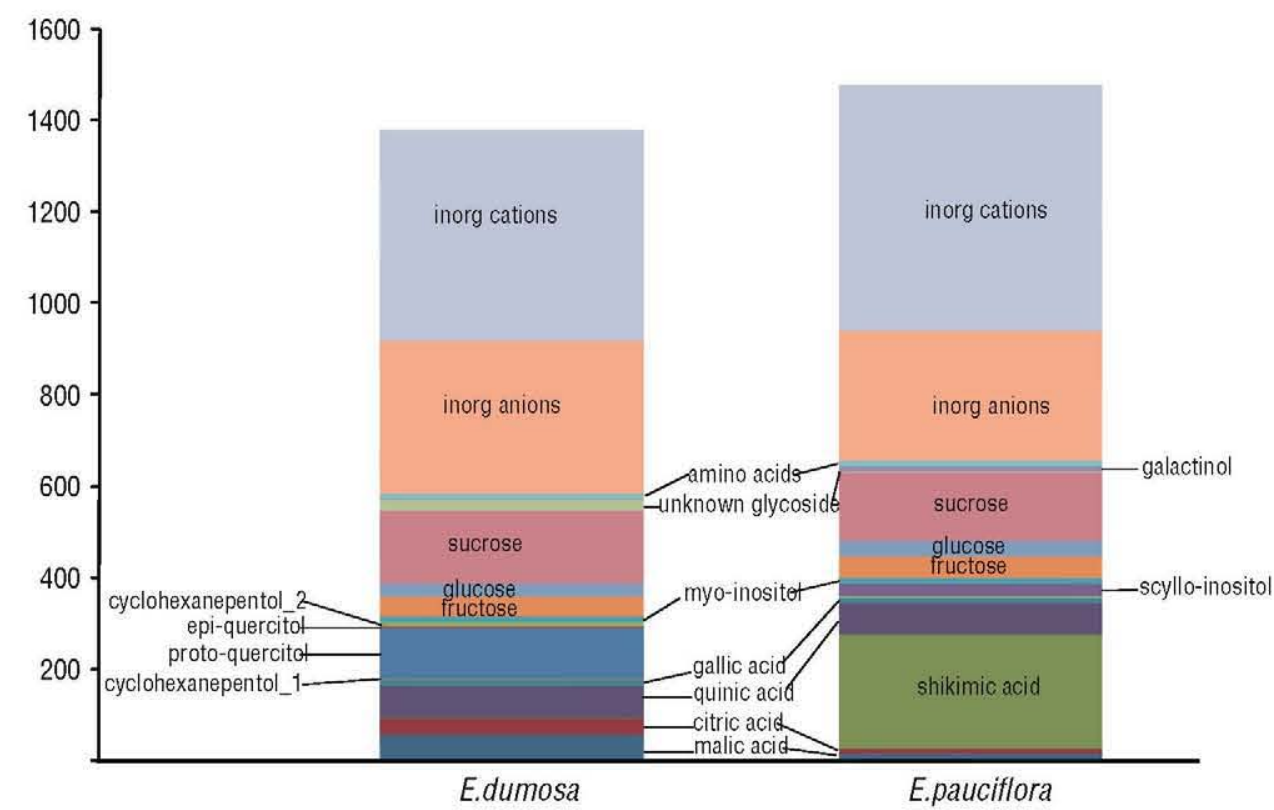



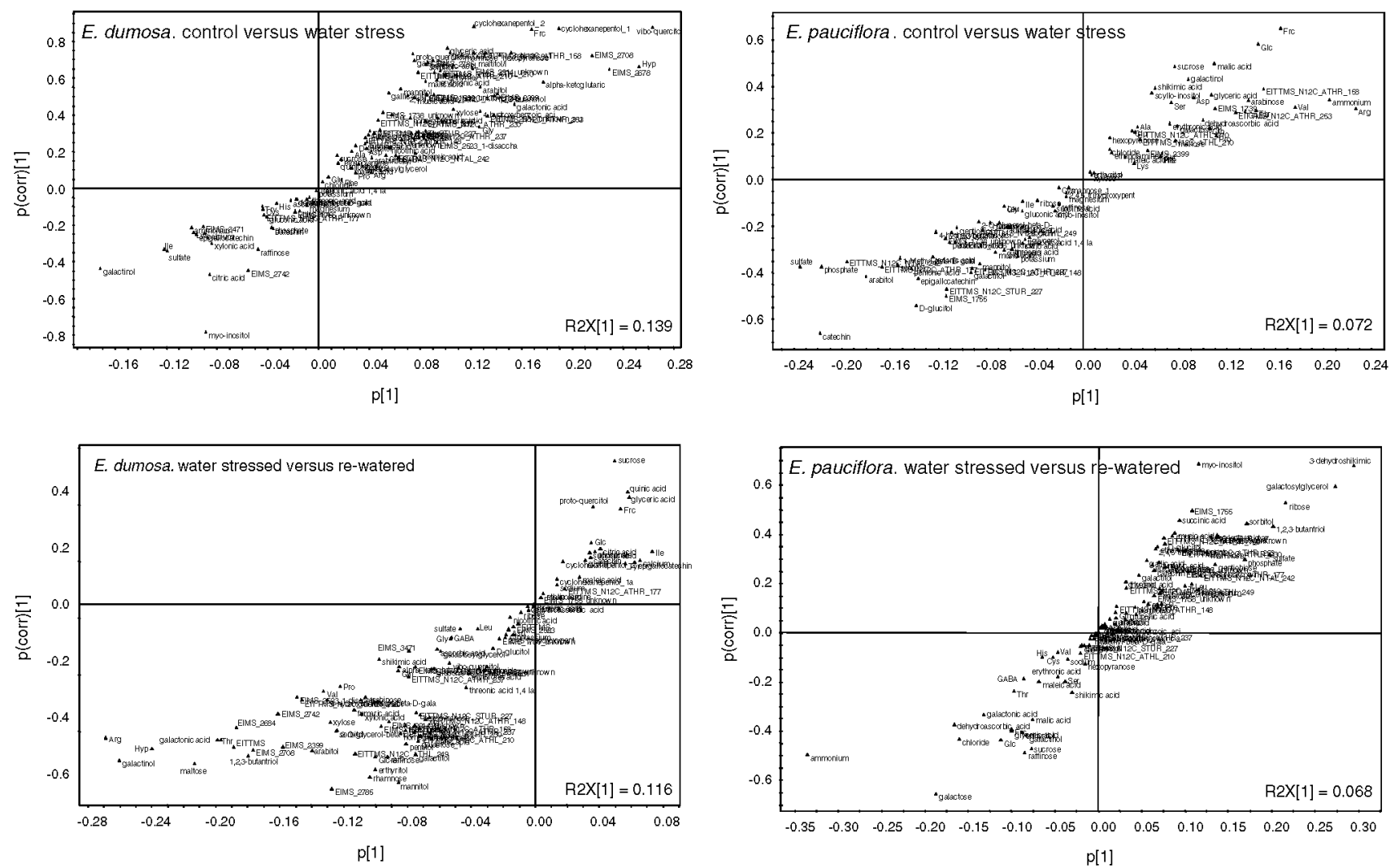

Fig. 3 S-plots of OPLS-DA models for E. dumosa (left) and E. pauciflora (right) contrasting control with water stress (top row), or water stressed with re-watered (bottom row). The $x$ axis is the $P$ loading profile of the predictive component (i.e. related to water stress or re-watering) of the OPLS-DA model, while the $y$ axis is the

were molecules that were decreased significantly (3/13 metabolites) or non-significantly $(10 / 13)$ by water stress (Fig. 5). Metabolites that were decreased by re-watering included the four abundant metabolites that were responsible for much of the osmotic adjustment induced by water stress (fructose, glucose, sucrose, malic acid), two carbohydrates that were unaffected by water stress (raffinose and galactose), ammonium (which had a non-significant increase under water stress) and chloride (unaffected by water stress).

\section{Discussion}

\subsection{Leaf metabolite profiles: differences between species}

GC and GC-MS based metabolite profiling has a long history of use in plants (Knights 1967) with earlier works focusing on profiles of one class of compounds. More recently the focus has shifted to profiling of multiple compound classes (Adams et al. 1999) and so-called

$P$ correlation loading vector of the predictive component of the OPLS-DA model. Metabolites in the upper right quadrant of S-plots are at greater concentrations in water stressed than control plants (top row), or at greater concentrations in re-watered plants than waterstress plants (bottom row)

unbiased metabolomic techniques (Roessner et al. 2000). The past decade has seen widespread application of unbiased GC-MS based metabolite profiling, but few studies on Eucalyptus spp.—one of the most economically and ecologically important genera of trees. The metabolite profiles obtained here complement and significantly expand upon studies profiling amino acids (Adams et al. 1995); amino and organic acids (Chen et al. 1998); carbohydrates (Merchant et al. 2006a), amino acids, organic acids and carbohydrates (Adams et al. 1999). The GC-MS profiling method permitted analysis of many metabolites of primary metabolism, but inherent limitations of GC-MS meant that we were unable to quantify metabolites that were labile (e.g. degraded during extraction, derivatisation or injection), larger than about $500 \mathrm{Da}$ or highly polar(e.g. phenolics that can best be quantified by LC/MS methods, Close and Beadle 2003). Hence, our analyses are essentially blind to a significant proportion of the metabolome.

This study adds an extra dimension to earlier targeted analyses of carbohydrates that reported a dichotomy between those Eucalyptus species that contain protoquercitol and those that do not (e.g. Merchant et al. 2006a, 


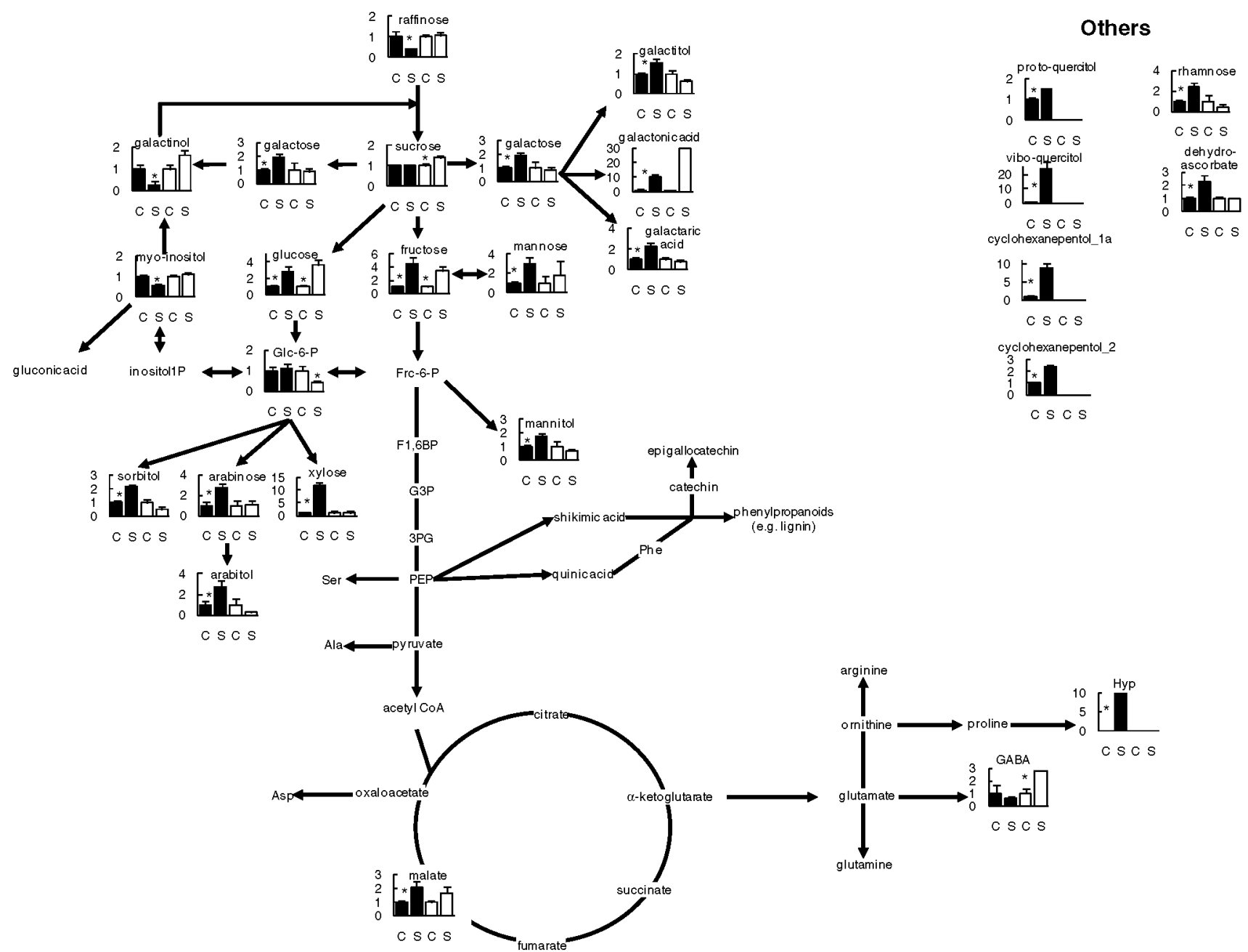

Fig. 4 Mapping of relative metabolite concentrations on known pathways for leaves of $E$. dumosa (black columns) and $E$. pauciflora (grey columns) grown with adequate water (C) or severe water stress(S). Data are normalized (to 1) of the mean concentration in control plants. Data are mean and standard error of five replicate plants. Column graphs are shown only for those metabolites with

b) and the more general observation that even closely related genotypes (e.g. cultivars) can have contrasting metabolite profiles (Foito et al. 2009). As expected, we found that $E$. dumosa contained large amounts of protoquercitol (around $1 \%$ of dry mass in control plants) whereas proto-quercitol was absent or below detection limits in E. pauciflora (Fig. 2). This was not the only difference in metabolites between species. 8 metabolites detected in E. pauciflora were absent or below detection limits in $E$. dumosa, while 19 detected in $E$. dumosa were absent or below detection limits in E. pauciflora. There were also striking quantitative differences between species with the profile of polar organic metabolites in E. dumosa dominated by proto-quercitol and common carbohydrates (fructose, glucose, sucrose), while E. pauciflora was dominated by shikimic acid and common carbohydrates. significant differences in either species. The significance of differences between control and water stressed was determined by $t$ test and is indicated by an asterisk. Metabolites written in black were detected but were not significantly affected by water stress. Metabolites in grey were not detected. Many metabolites have been omitted from this graph because they were unaffected by water stress

We believe that ours is the first report showing concentrations of shikimic acid vary enormously between Eucalyptus species and it may be the single most abundant organic solute in leaves. Our results are not unprecedented because an early TLC study with Eucalyptus siberiana reported concentrations of shikimic acid from 1 to $6.5 \%$ of dry mass (Hillis 1959) and concentrations greater than 1\% of dry mass have been reported from a variety of gymnosperms (Hattori et al. 1954; Li et al. 2010), Illicium verum (Liu et al. 2009) and Illicium anisatum (Urakami et al. 2010). Hence, super-abundant shikimic acid is comparatively common yet we do not know the functional significance of large amounts of shikimic acid. One role for shikimic acid is its contribution to osmotic pressure. In E. pauciflora it was the single most abundant organic solute in leaves and contributed $0.6-0.8 \mathrm{MPa}$ to osmotic pressure, 
Fig. 5 Shared and unique structures plots (SUS) comparing OPLS-DA models of control versus with OPLS-DA models of stressed versus rewatered. Corresponding S-plots are shown in Fig. 3 and jack-knifed confidence intervals in Supplementary Table 1 . Note that $y$-axes in SUS plots were reversed (multiplied by -1 ) to enable a more logical comparison of stress treatment (vs. control plants) and rewatering (vs. stressed plants). Metabolites that fall on or near the diagonal lines have similar multivariate structures. Water stress treatment and rewatering have opposite effects on metabolites close to the diagonal line from lower left to upper right, whereas water stress treatment and rewatering have the same effect on metabolites near the diagonal line from upper left to lower right
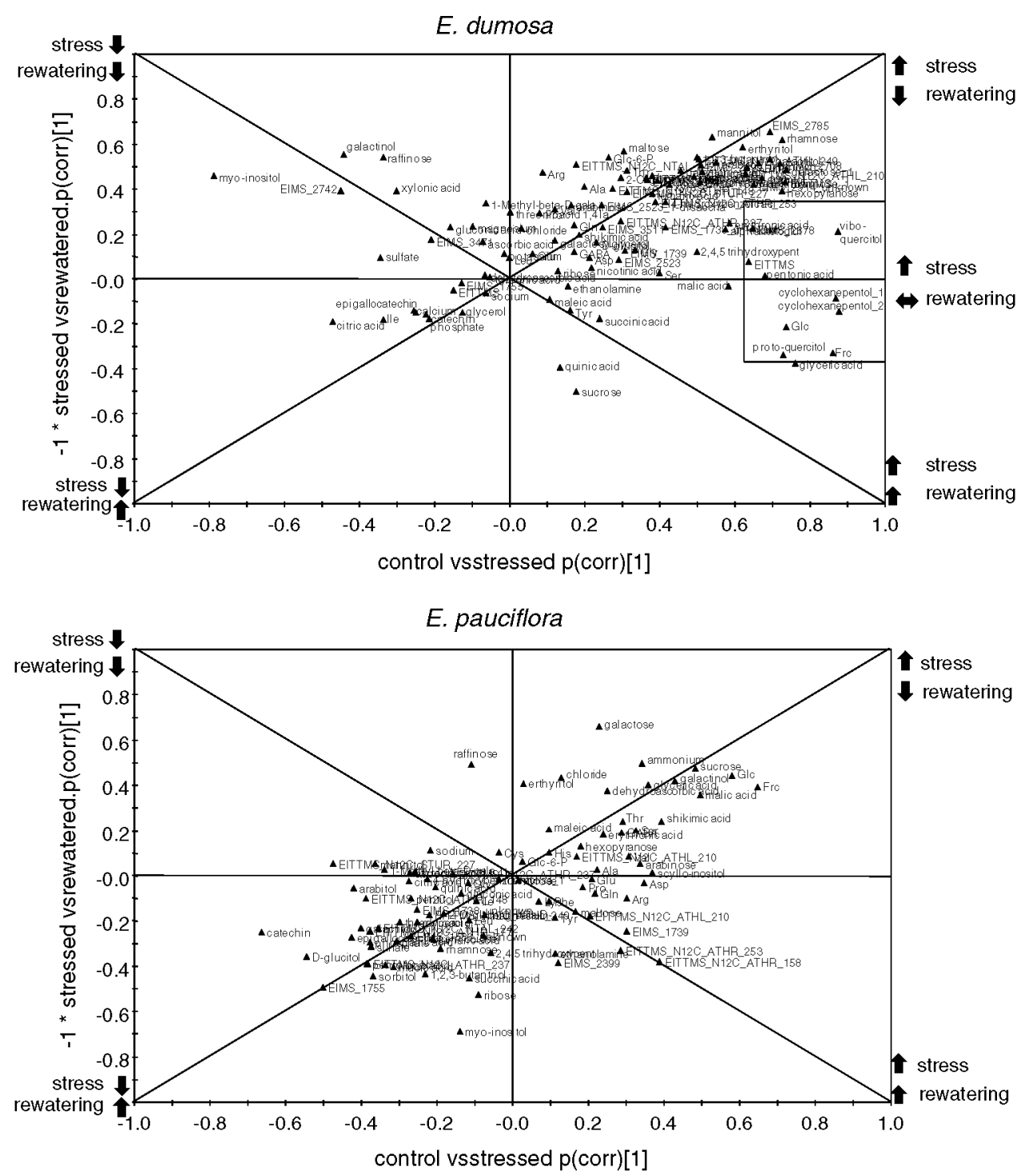

and thus more than compensated for the absence of protoquercitol (proto-quercitol in E. dumosa contributed $0.3-0.4 \mathrm{MPa}$ to osmotic pressure). This is supported by preliminary analysis of six additional Eucalyptus species that showed species that contain proto-quercitol contain small amounts of shikimic acid, whereas those that do not contain proto-quercitol contain very large amounts of shikimic acid (commonly $2-5 \%$ of dry mass). The other obvious role for shikimic acid is as a precursor to aromatic amino acids and a variety of secondary metabolites (Bennett and Wallsgrove 1994; Liu et al. 2009). Therefore, differences in amounts of shikimic acid could be related to its downstream metabolism, e.g. synthesis of different secondary metabolites. To determine the significance and taxonomic patterns in super-abundant shikimic acid requires additional GC-MS profiling plus profiling of secondary metabolites (e.g. by LC-MS) on some of the $>700$ species of Eucalyptus.
It has been claimed that proto- and vibo-quercitol are the only two cyclohexanepentol stereoisomers that occur in nature (Marasu et al. 1998; Jakobsen et al. 2007), but results from this study indicate four additional cyclohexanepentol stereoisomers occur in E. dumosa. In addition to the well-known occurrence of proto-quercitol and viboquercitol (Figs. 2, 5, see also: Plouvier 1963; Adams et al. 2005; Merchant and Adams 2005; Merchant et al. 2006a, b; Arndt et al. 2008), all E. dumosa contained two cyclohexanepentol stereoisomers ( $R I=1764$ and 1871), while in a minority of $E$. dumosa we also detected trace amounts of epi-quercitol and another cyclohexanepentol stereoisomer $(\mathrm{RI}=1768)$. The occurrence of more than two stereoisomers ought not be that surprising given that the cyclohexanepentol family comprises 16 stereoisomers and plants often contain multiple stereoisomers (e.g. of the related inositols). We are confident that the unknowns are cyclohexanepentol stereoisomers because their EI and 
methane CI mass spectra matched $>90 \%$ to the three cyclohexanepentols for which standards are commercially available (proto-quercitol, epi-quercitol, vibo-quercitol). The match with CI is particularly convincing because less extensive fragmentation with methane CI resulted in abundant $\mathrm{MH}+$ for all monosaccharides and cyclic polyols, and these combined with neutral losses (e.g. M-105 and M-179 common to all cyclic polyols) produce distinctive mass spectra for cyclohexanepentols. The cyclohexanepentol stereoisomers are unlikely artefacts of derivitisation (e.g. epimerisation products) because derivitisation of purified standards of proto-quercitol, vibo-quercitol and epi-quercitol did not give rise to additional cyclohexanepentol stereoisomers. Determination of stereoisomer identity requires synthesis of the suite of cyclohexanepentol stereoisomers followed by GC-MS, and/or NMR.

\subsection{Response of leaf metabolites to water stress}

Water stress affected approximately $30-40 \%$ of measured metabolites in $E$. dumosa with carbohydrates the main compound class affected by water stress. Data indicate a major shift in $\mathrm{C}$ partitioning away from the raffinose/ stachyose pathway and into cyclohexanepentols, monosaccharides, acyclic sugar alcohols and sugar acids (Fig. 4). The shift in carbohydrate partitioning is likely an adaptive response that helps plants cope with water stress via osmotic and non-osmotic mechanisms. For example, increases in fructose and glucose made a large contribution to osmotic adjustment (Merchant et al. 2006b; Warren et al. 2007; Foito et al. 2009), while the increases in acyclic polyols are consistent with studies showing increases in acyclic polyols under water stress due to their non-osmotic protective functions (Karakas et al. 1997; Shen et al. 1999; Abebe et al. 2003; Li and $\mathrm{Li}$ 2005). Increases in some of the key components of cell walls (Keegstra et al. 1973), viz., four minor monosaccharides (xylose, arabinose, rhamnose) and two sugar acids (galactonic acid and galactaric acid) suggest that an additional way $E$. dumosa may have coped with water stress was by increasing synthesis or changing the composition of cell walls, as has been found in other species subjected to water stress (Joly and Zaerr 1987; Zwiazek 1991).

Partitioning of more carbohydrates to cyclohexanepentols may confer benefits in terms of osmoprotection and help explain the reductions in the raffinose/stachyose pathway. It is suggested that cyclic polyols (e.g. cyclohexanepentols) function as stable osmo- and thermo-protectants (e.g. Orthen and Popp 2000; Jaindl and Popp 2006). Sub-cellular localisation is an important aspect of functioning as an osmo-protectant because of the need to maintain osmotic pressure while keeping potentially damaging solutes compartmentalised from the easily damaged cellular components (e.g. chloroplasts, mitochondria) (Bohnert and Shen 1999). There is no information on subcellular localisation of cyclohexanepentols in Eucalyptus, though it is speculated that proto-quercitol is distributed throughout the cell due to its very high concentration (Arndt et al. 2008). Vibo-quercitol, cyclohexanepentol_1 and cyclohexanepentol_2 may also occur throughout the cell, but owing to their smaller concentrations and large relative increases under water stress (e.g. 23 -fold increase in vibo-quercitol) it is tempting to speculate that these less abundant cyclohexanepentols are synthesised under water stress and localised in the small volume of the cytosol so as to increase effective concentrations (sensu Munns 2002). Alternatively, or additionally, these minor cyclohexanepentols may play non-osmotic, non-concentration dependent roles (e.g. stabilisation of membranes).

Water stress affected a smaller number of metabolites in $E$. pauciflora, but as with $E$. dumosa carbohydrates were the compound class most affected. The most notable effect was increases in fructose, glucose and sucrose. These increases likely occurred because growth was more sensitive to water stress than photosynthesis (Chaves et al. 2003) and water deficits led to changes in $\mathrm{C}$ partitioning (Xue et al. 2008) (Fig. 4). Increases in sucrose and decreases in glucose-6-P in $E$. pauciflora are possibly consequences of increased flux to sucrose due to decreased activity of hexokinase (Glc $\rightarrow$ Glc-6-P) and phosphoglucomutase (Glc-6-P $\leftrightarrow$ Glc-1-P) coupled with increases of sucrose synthase (Frc + UDP-Glc $\rightarrow$ Suc) (Xue et al. 2008). This pattern of increased sucrose and decreased Glc-6-P was reversed upon re-watering $E$. pauciflora, which strengthens the case for this being a reversible change in $C$ partitioning.

Organic/phenolic acids and amino acids were generally unaffected by water stress in either species. The only exceptions were large relative increases in hydroxyproline in $E$. dumosa that may help protect membranes and proteins under water stress (Nanjo et al. 1999; Lawlor and Cornic 2002), and increases in GABA in E. pauciflora which is indicative of operation of the GABA shunt (Fig. 4, see also Shelp et al. 1999; Allan et al. 2008). There was no evidence that water stress affected the phenylpropanoid pathway in either species, which is at odds with observations that many aspects of phenylpropanoid metabolism are responsive to stress (Dixon and Paiva 1995; Graham and Graham 1996; Salekdeh et al. 2002; Singh et al. 2009), but may reflect inherent limitations of GC-MS for quantification of phenylpropanoids.

Re-watering reversed changes in many of the metabolites affected by water stress, but there were differences between species and some metabolites were notable exceptions (e.g. cyclohexanepentols, Fig. 5). In E. dumosa the majority of metabolites increased by water stress were 
subsequently decreased by re-watering. However, despite the many metabolites decreased by re-watering there were additional decreases in osmotic potential and increases in total measured metabolites due to modest increases in a number of abundant metabolites (fructose, glucose, sucrose, proto-quercitol) (Table 1, Figs. 1, 4). This pattern of decreased osmotic potential due to re-watering has been seen in other Eucalyptus species (Myers and Neales 1986; Guarnaschelli et al. 2003) and is suggested to help the plant cope with future water stress by maintaining higher pressure potential to permit stomatal opening and improve gas exchange under future water stress (Turner and Jones 1980; Morgan 1984). In E. pauciflora, by contrast, osmotic potential was increased by re-watering and total measured metabolites decreased (Table 1, Figs. 1,4). This reduction in osmolytes, accumulated during osmotic adjustment, could be associated with synthesis of new biomass.

\section{Conclusions}

This experiment has shown that two Eucalyptus species have similarities and differences in leaf chemistry and how they respond to water stress and re-watering. Measurements on many more Eucalyptus species are required to determine if the dichotomy between $E$. dumosa and E. paucifora reflects a general dichotomy between Eucalyptus species from mesic versus semi-arid habitats, or a dichotomy related to phylogenetic relationships, or if E. dumosa and E. paucifora are extremes on a continuum. Our use of a less biased metabolomic approach has highlighted that water stress affects a larger number of metabolites than was reported from previous targeted analyses with Eucalyptus. For example, we demonstrate for the first time in Eucalyptus that water stress affects a large number of low abundance compounds that may help plants cope with water stress via non-osmotic roles. These low abundance compounds were missed in earlier targeted analyses due to their focus on a handful of high abundance compounds that are putative osmolytes. Another notable outcome from our less biased approach was that shikimic acid can be the single most abundant organic metabolite in leaves of Eucalyptus, and clearly ought to be included in future targeted analyses used to construct osmotic budgets. Finally, we found that in addition to the well-known occurrence of proto- and vibo-quercitol, E. dumosa contains four additional cyclohexanepentol stereoisomers and at least two of these respond strongly to water stress.

Acknowledgments This work was supported by a Discovery Grant and QEII Fellowship from the Australian Research Council (CR Warren), and a major equipment grant from The University of Sydney. PhD fellowship from Regional Government of Madrid (FJ Cano) and in the frame of the project "SUM2008-00004-C03-01", funded by the Ministry of Science and Innovation of Spain. Dr Maria Taranto is warmly thanked for assisting with preparation of samples.

\section{References}

Abebe, T., Guenzi, A. C., Martin, B., \& Cushman, J. C. (2003). Tolerance of mannitol-accumulating transgenic wheat to water stress and salinity. Plant Physialogy, 131, 1748-1755.

Adams, M. A., Attiwill, P. M., \& Wang, L. M. (1995). Effects of phosphorus supply on growth and nitrogen fractions in xylem sap and foliage of Eucalyptus regnans (Muell. F.), Eucalyptus nitens (Maiden) and Eucalyptus globulus (Labill) seedlingsimplications for herbivory. Trees-Structure and Function, 9, 324-331.

Adams, M. A., Chen, Z. L., Landman, P., \& Colmer, T. D. (1999). Simultaneous determination by capillary gas chromatography of organic acids, sugars, and sugar alcohols in plant tissue extracts as their trimethylsilyl derivatives. Analytical Biochemistry, 266, $77-84$.

Adams, M. A., Richter, A., Hill, A. K., \& Colmer, T. D. (2005). Salt tolerance in Eucalyptus spp: identity and response of putative osmolytes. Plant Cell and Environment, 28, 772-787.

Allan, W. L., Simpson, J. P., Clark, S. M., \& Shelp, B. J. (2008). $\gamma$-hydroxybutyrate accumulation in Arabidopsis and tobacco plants is a general response to abiotic stress: putative regulation by redox balance and glyoxylate reductase isoforms. Journal of Experimental Botany, 59, 2555-2564.

Arndt, S. K., Livesley, S. J., Merchant, A., Bleby, T. M., \& Grierson, P. F. (2008). Quercitol and osmotic adaptation of field-grown Eucalyptus under seasonal drought stress. Plant Cell and Environment, 31, 915-924.

Barnett, N. M., \& Naylor, A. W. (1966). Amino acid and protein synthesis in Bermuda grass during water stress. Plant Physiology, 41, 1222-1230.

Bennett, R. N., \& Wallsgrove, R. M. (1994). Secondary metabolites in plant defense-mechanisms. New Phytologist, 127, 617-633.

Bohnert, H. J., \& Shen, B. (1999). Transformation and compatible solutes. Scientia Horticulturae, 78, 237-260.

Charlton, A. J., Donarski, J. A., Harrison, M., et al. (2008). Responses of the pea (Pisum sativum L.) leaf metabolome to drought stress assessed by nuclear magnetic resonance spectroscopy. Metabolomics, 4, 312-327.

Chaves, M. M., Maroco, J. P., \& Pereira, J. S. (2003). Understanding plant responses to drought-from genes to the whole plant. Functional Plant Biology, 30, 239-264.

Chen, Z. L., Landman, P., Colmer, T. D., \& Adams, M. A. (1998). Simultaneous analysis of amino and organic acids in extracts of plant leaves as tert-butyldimethylsilyl derivatives by capillary gas chromatography. Analytical Biochemistry, 259, 203-211.

Close, D. C., \& Beadle, C. L. (2003). Alternate energy dissipation? Phenolic metabolites and the xanthophyll cycle. Journal of Plant Physiology, 160, 431-434.

Dixon, R. A., \& Paiva, N. L. (1995). Stress-induced phenylpropanoid metabolism. Plant Cell, 7, 1085-1097.

Dreyer, E., Bousquet, F., \& Ducrey, M. (1990). Use of pressure volume curves in water relation analysis on woody shoots: influence of rehydration and comparison of four European oak species. Annals of Forest Science, 47, 285-297.

Fiehn, O. (2002). Metabolomics-the link between genotypes and phenotypes. Plant Molecular Biology, 48, 155-171.

Foito, A., Byrne, S. L., Shepherd, T., Stewart, D., \& Barth, S. (2009). Transcriptional and metabolic profiles of Lolium perenne $\mathrm{L}$. 
genotypes in response to a PEG-induced water stress. Plant Biotechnology Journal, 7, 719-732.

Graham, T. L., \& Graham, M. Y. (1996). Signaling in soybean phenylpropanoid responses. Dissection of primary, secondary, and conditioning effects of light, wounding and elicitor treatments. Plant Physiology, 110, 1123-1133.

Guarnaschelli, A. B., Lemcoff, J. H., Prystupa, P., \& Basci, S. O. (2003). Responses to drought preconditioning in Eucalyptus globulus Labill. provenances. Trees-Structure and Function, 17, 501-509.

Hare, P. D., Cress, W. A., \& Van Staden, J. (1998). Dissecting the roles of osmolyte accumulation during stress. Plant Cell and Environment, 21, 535-553.

Hattori, S., Yoshida, S., \& Hasegawa, M. (1954). Occurrence of shikimic acid in the leaves of gymnosperms. Physiologia Plantarum, 7, 283-289.

Hillis, W. E. (1959). Shikimic acid in the leaves of Eucalyptus sieberiana f muell. Journal of Experimental Botany, 10, 87-89.

Hinckley, T. M., Duhme, F., Hinckley, A. R., \& Richter, H. (1980). Water Relations of Drought Hardy Shrubs - Osmotic Potential and Stomatal Reactivity. Plant Cell and Environment, 3, 131-140.

Hsiao, T. C. (1973). Plant responses to water stress. Annual Review of Plant Physiology and Plant Molecular Biology, 24, 519-570.

Jaindl, M., \& Popp, M. (2006). Cyclitols protect glutamine synthetase and malate dehydrogenase against heat induced deactivation and thermal denaturation. Biochemical and Biophysical Research Communications, 345, 761-765.

Jakobsen, A. N., Aasen, I. M., \& Strom, A. R. (2007). Endogenously synthesized (-)-proto-quercitol and glycine betaine are principal compatible solutes of Schizochytrium sp strain S8 (ATCC 20889) and three new isolates of phylogenetically related thraustochytrids. Applied and Environmental Microbiology, 73, $5848-5856$.

Joly, R. L., \& Zaerr, J. B. (1987). Alteration of cell-wall water content and elasticity in Douglas fir during periods of water deficit. Plant Physiology, 83, 418-422.

Karakas, B., OziasAkins, P., Stushnoff, C., Suefferheld, M., \& Rieger, M. (1997). Salinity and drought tolerance of mannitol-accumulating transgenic tobacco. Plant Cell and Environment, 20, 609-616.

Keegstra, K., Talmadge, K. W., Bauer, W. D., \& Albersheim, P. (1973). The Structure of Plant Cell Walls: III. A model of the walls of suspension-cultured sycamore cells based on the interconnections of the macromolecular components. Plant Physiology, 51, 188-196.

Knights, B. A. (1967). Identification of plant sterols using combined GLC/mass spectrometry. Journal of Gas Chromatography, 5, 273.

Kramer, P. J., \& Boyer, J. S. (1995). Water relations of plants and sails. San Diego: Academic Press.

Kubiske, M. E., \& Abrams, M. D. (1991). Seasonal, diurnal and rehydration-induced variation of pressure-volume relationships in Pseudotsuga menziesii. Physiologia Plant, 83, 107-116.

Ladiges, P. Y. (1975). Some Aspects of tissue water relations in 3 populations of Eucalyptus viminalis Labill. New Phytologist, 75, $53-62$.

Lawlor, D. W., \& Cornic, G. (2002). Photosynthetic carbon assimilation and associated metabolism in relation to water deficits in higher plants. Plant Cell and Environment, 25, 275-294.

Lemcoff, J. H., Guarnaschelli, A. B., Garau, A. M., \& Prystupa, P. (2002). Elastic and osmotic adjustments in rooted cuttings of several clones of Eucalyptus camaldulensis Dehnh. from southeastern Australia after a drought. Flora, 197, 134-142.

Li, T. H., \& Li, S. H. (2005). Leaf responses of micropropagated apple plants to water stress: nonstructural carbohydrate composition and regulatory role of metabolic enzymes. Tree Physiology, 25, 495-504.

Li, C. X., Zhong, Z. C., Geng, Y. H., \& Schneider, R. (2010). Comparative studies on physiological and biochemical adaptation of Taxodium distichum and Taxodium ascendens seedlings to different soil water regimes. Plant and Soil, 329, 481-494.

Lippold, F., Sanchez, D. H., Musialak, M., et al. (2009). AtMyb41 regulates transcriptional and metabolic responses to osmotic Stress in Arabidopsis. Plant Physiology, 149, 1761-1772.

Lisec, J., Schauer, N., Kopka, J., Willmitzer, L., \& Fernie, A. R. (2006). Gas chromatography mass spectrometry-based metabolite profiling in plants. Nature Protocols, 1, 387-396.

Liu, H. C., Li, Q. W., Zhang, Y., \& Zhou, Y. H. (2009). Analysis of (-)-shikimic acid in Chinese star anise by GC-MS with selected ion monitoring. Chromatographia, 69, 339-344.

Macfarlane, C., White, D. A., \& Adams, M. A. (2004). The apparent feed-forward response to vapour pressure deficit of stomata in droughted, field-grown Eucalyptus globulus Labill. Plant Cell and Environment, 27, 1268-1280.

Marasu, A., Secuen, H., Sutbeyaz, Y., \& Balci, M. (1998). A convenient synthesis of talo-quercitol (1-Deoxy-neo-Inositol) and vibo-quercitol (1-Deoxy-myo-Inositol) via ene reaction of singlet oxygen. Journal of Organic Chemistry, 63, 2039-2041.

Marsh, N. R., \& Adams, M. A. (1995). Decline of Eucalyptus tereticomis near Bairnsdale, Victoria: Insect Herbivory and Nitrogen Fractions in Sap and Foliage. Australian Journal of Botany, 43, 39-49.

Mawhinney, T. P., Robinett, R. S. R., Atalay, A., \& Madson, M. A. (1986). Analysis of amino-acids as their tert-butyldimethylsilyl derivatives by gas-liquid-chromatography and mass-spectrometry. Joumal of Chromatography, 358, 231-242.

Medrano, H., Bota, J., Abadia, A., Sampol, B., Escalona, J. M., \& Flexas, J. (2002). Effects of drought on light-energy dissipation mechanisms in high-light-acclimated, field-grown grapevines. Functional Plant Biology, 29, 1197-1207.

Merchant, A., \& Adams, M. (2005). Stable osmotica in Eucalyptus spathulata - responses to salt and water deficit stress. Functional Plant Biology, 32, 797-805.

Merchant, A., Arndt, S.K., Douglas, M.R., et al. (2010). Seasonal changes in carbohydrates, cyclitols, and water relations of 3 field grown Eucalyptus species from contrasting taxonomy on a common site. Annals of Forest Science, 67. doi:10.1051/forest/ 2009085.

Merchant, A., Richter, A., Popp, M., \& Adams, M. A. (2006a). Targeted metabolic profiling provides a functional link among eucalypt taxonomy, physiology and evolution. Phytochemistry, 67, 402-408.

Merchant, A., Tausz, M., Arndt, S. K., \& Adams, M. A. (2006b). Cyclitols and carbohydrates in leaves and roots of 13 Eucalyptus species suggest contrasting physiological responses to water deficit. Plant Cell and Environment, 29, 2017-2029.

Morgan, J. M. (1984). Osmoregulation and Water-Stress in HigherPlants. Annual Review of Plant Physiology and Plant Molecular Biology, 35, 299-319.

Munns, R. (2002). Comparative physiology of salt and water stress. Plant Cell and Environment, 25, 239-250.

Myers, B. A., \& Neales, T. F. (1986). Osmotic Adjustment, Induced by Drought, in Seedlings of 3 Eucalyptus Species. Aust. Journal of Plant Physiology, 13, 597-603.

Nanjo, T., Kobayashi, M., Yoshiba, Y., et al. (1999). Biological functions of proline in morphogenesis and osmotolerance revealed in antisense transgenic Arabidopsis thaliana. Plant Journal, 18, 185-193.

Orthen, B., \& Popp, M. (2000). Cyclitols as cryoprotectants for spinach and chickpea thylakoids. Environmental and Experimental Botany, 44, 125-132. 
Plouvier, V. (1963). Distribution of aliphatic polyols and cyclitols. In T. Swain (Ed.), Chemical plant taxonomy (pp. 313-336). London: Academic Press.

Rawat, J. S., \& Banerjee, S. P. (1998). The influence of salinity on growth, biomass production and photosynthesis of Eucalyptus camaldulensis Dehnh. and Dalbergia sissoo Roxb. seedlings. Plant and Soil, 205, 163-169.

Robichaux, B. S. (1984). Variation in the tissue water relations of two sympatric Hawaiian Dubautia species and their natural hybrid. Oecologia, 65, 75-81.

Roessner, U., Wagner, C., Kopka, J., Trethewey, R. N., \& Willmitzer, L. (2000). Simultaneous analysis of metabolites in potato tuber by gas chromatography-mass spectrometry. Plant Joumal, 23, 131-142.

Salekdeh, G. H., Siopongco, J., Wade, L. J., Ghareyazie, B., \& Bennett, J. (2002). A proteomic approach to analyzing droughtand salt-responsiveness in rice. Field Crops Research, 76, 199-219.

Sanchez, D. H., Szymanski, J., Erban, A., Udvardi, M. K., \& Kopka, J. (2010). Mining for robust transcriptional and metabolic responses to long-term salt stress: a case study on the model legume Lotus japonicus. Plant Cell and Environment, 33, 468-480.

Schauer, N., Steinhauser, D., Strelkov, S., et al. (2005). GC-MS libraries for the rapid identification of metabolites in complex biological samples. FEBS Letters, 579, 1332-1337.

Shao, H. B., Chu, L. Y., Jaleel, C. A., Manivannan, P., Panneerselvam, R., \& Shao, M. A. (2009). Understanding water deficit stressinduced changes in the basic metabolism of higher plants biotechnologically and sustainably improving agriculture and the ecoenvironment in arid regions of the globe. Critical Reviews in Biotechnology, 29, 131-151.

Shelp, B. J., Bown, A. W., \& McLean, M. D. (1999). Metabolism and functions of gamma-aminobutyric acid. Trends in Plant Science, $4,446-452$.

Shen, B., Hohmann, S., Jensen, R. G., \& Bohnert, H. J. (1999). Roles of sugar alcohols in osmotic stress adaptation. Replacement of glycerol by mannitol and sorbitol in yeast. Plant Physiology, $121,45-52$.

Singh, K., Kumar, S., Rani, A., Gulati, A., \& Ahuja, P. (2009). Phenylalanine ammonia-lyase (PAL) and cinnamate 4-hydroxylase $(\mathrm{C} 4 \mathrm{H})$ and catechins (flavan-3-ols) accumulation in tea. Funct. Integrated Genomics, 9, 125-134.
Sumner, L. W., Amberg, A., Barrett, D., et al. (2007). Proposed minimum reporting standards for chemical analysis. Metabolomics, 3, 211-221.

Tuomela, K. (1997). Leaf water relations in six provenances of Eucalyptus microtheca: A greenhouse experiment. Forest Ecology and Management, 92, 1-10.

Turner, N. C. (1986). Adaptation to water deficits-a changing perspective. Australian Joumal of Plant Physiology, 13, 175-190.

Turner, N. C., \& Jones, M. M. (1980). Turgor maintenance by osmotic adjustment: a review and evaluation. In N. C. Turner \& P. J. Kramer (Eds.), Adaptation of plants to water and high temperature stress (pp. 155-172). New York: Wiley-InterScience.

Tyree, M. T., Cheung, Y. N. S., MacGregor, M. E., \& Talbot, A. J. B. (1978). The characteristics of seasonal and ontogenetic changes in the tissue-water relations of Acer, Populus, Tsuga and Picea. Canadian Joumal of Botany, 56, 635-647.

Tyree, M. T., \& Hammel, H. T. (1972). Measurement of the turgor pressure and the water relations of plants by the pressure-bomb technique. Journal of Experimental Botany, 23, 267-282.

Urakami, K., Zangiacomi, V., Yamaguchi, K., \& Kusuhara, M. (2010). Quantitative metabolome profiling of Illicium anisatum by capillary electrophoresis time-of-flight mass spectrometry. Biomedical Research-Tokyo, 31, 161-163.

Warren, C. R. (2009). Why is uptake of inorganic N favoured by high temperatures and amino acids by low temperatures? Soil Biology and Biochemistry, 41, 778-784.

Warren, C. R., \& Adams, M. A. (2004). Capillary electrophoresis of the major anions and cations in leaf extracts of woody species. Phytochemical Analysis, 15, 407-413.

Warren, C. R., Bleby, T. M., \& Adams, M. A. (2007). Changes in gas exchange versus leaf solutes as a means to cope with summer drought in Eucalyptus marginata. Oecologia, 154, 1-10.

Xue, G. P., McIntyre, C. L., Glassop, D., \& Shorter, R. (2008). Use of expression analysis to dissect alterations in carbohydrate metabolism in wheat leaves during drought stress. Plant Molecular Biology, 67, 197-214.

Zwiazek, J. J. (1991). Cell-wall changes in white spruce (Picea glauca) needles subjected to repeated drought stress. Physiologia Plant, 82, 513-518. 